Classification

Physics Abstracts

34.80D $-73.40 \mathrm{~L}-82.80$

\title{
Spatially resolved EELS of GaAs/GaAlAs heterostructures
}

\author{
Hubert Lakner, Ludwig Josef Balk and Erich Kubalek
}

Werkstoffe der Elektrotechnik, Sonderforschungsbereich 254, Universităt Duisburg, Kommandantenstrasse 60, D-4100 Duisburg 1, Germany

(Received November 14, 1990; accepted January 28, 1991)

\begin{abstract}
Using typical beam parameters of the STEM and a parallel detector for the EEL spectra it is possible to detect principally the $\mathrm{Al}-\mathrm{L}$ and $\mathrm{Al}-\mathrm{K}$ edge in a $\mathrm{GaAs} / \mathrm{Ga}_{(1-x)} \mathrm{Al}$ 到 $\mathrm{As}$ heterostructure with a spatial resolution better than $2 \mathrm{~nm}$, if the relative $\mathrm{Al}$ concentration is higher than $x=0.2$. However, quantification of the $\mathrm{Al}$ edges is difficult due to minor As edges in front of the $\mathrm{Al}$ edges and a weak signal to noise ratio of the $\mathrm{Al}$ edges. Thus, for quantitative microanalysis the Ga-L edge is much more suitable. After background subtraction it is possible to determine the Ga concentration with an accuracy of $x \leq 0.05$ in $(1-x)$. Therefrom the Al concentration $x$ can be calculated. The spectra taken with different probe currents demonstrate that very small probe currents $(5 \mathrm{pA})$ and probe diameters down to the limit of $0.2 \mathrm{~nm}$ can be used to perform chemical analysis of GaAs/GaAlAs heterostructures.
\end{abstract}

\section{Introduction.}

Lattice matched $\mathrm{GaAs} / \mathrm{GaAlAs}$ interfaces play an important role in heterojunction devices. Chemically abrupt interfaces are essential for high device performance such as of heterostructure fieldeffect transistors [1]. The Al-concentration $x$ determines the bandgap and the refractive index of $\mathrm{Ga}_{(1-x)} \mathrm{Al}_{x}$ As layers important for applications in optoelectronic devices [2]. Typical layer thicknesses are in the $\mathrm{nm}$ range and less (down to one monolayer [3]. Therefore spatially resolved characterisation techniques are required for such structures. The spatial resolution of electron energy loss spectroscopy (EELS) of thin specimens is governed by the lateral dimensions of the electron probe and should be under that point of view superior to $\mathrm{X}$-ray microanalysis, where spatial resolution is limited by elastic scattering [4].

On the other hand the electron probe should contain as much current as possible in order to get sufficient signal to noise ratios in microanalytical measurements. Only a scanning transmission electron microscope (STEM) equipped with a cold field-emission source provides beam parameters which allow microanalytical work to be performed with optimum spatial resolution. Typical beam parameters at $100 \mathrm{keV}$ are $1 \mathrm{~nm}$ probe diameter and $1 \mathrm{nA}$ probe current. Using a special pole piece in a STEM probe diameters in the range of $0.2 \mathrm{~nm}$ but with small probe current (5 pA) can be achieved [5]. Therefore EELS in a field-emission STEM should offer a subnanometer resolution. 
Using serial detectors for EELS long exposure times may cause both beam damage to the specimen and decreased spatial resolution due to system instabilities. By means of a parallel detector EEL-spectra can be recorded in much shorter time with therefore better spatial resolution and with smaller radiation dose to the specimen $[6,7]$. The combination of a field-emission STEM equipped with a high resolution pole piece and a parallel detector for the EEL spectra is therefore the most promising technique for high spatial resolution microanalysis presently [8].

The spatially resolved determination of $x$ in the $\mathrm{Ga}_{(1-x)} \mathrm{Al}_{x}$ As layers can be done using either the $\mathrm{Ga}$ or the Al edge. Unfortunately the detection and quantification of the Al edges in GaAlAs is very difficult in EELS. It was reported that up to $x=0.25 \mathrm{Al}$ in $\mathrm{Ga}_{(1-x)} \mathrm{Al}_{x} \mathrm{As}_{\text {does not lead }}$ to an obvious Al-K edge in serial EELS [9]. Additionally the minor As- $\mathrm{L}_{1}$ edge close to the Al-K edge causes trouble in background estimation of the Al-K edge.

It is the intention of this paper to report on the application of spatially resolved EELS with parallel detection to GaAs/GaAlAs heterostructures in a field-emission STEM using small electron probes and therefore small probe currents. By doing so comparisons are made for using the $\mathrm{Ga}$ and the $\mathrm{Al}$ edges for the determination of the parameter $x$.

\section{Experimental procedure.}

All spectra and micrographs were recorded in a field-emission STEM (VG microscopes: HB 501) operated at $100 \mathrm{keV}$. The micrographs were obtained using high angle annular dark field and (200) dark field imaging techniques $[10,11]$. All spectra were recorded by additional use of a high resolution pole piece. The parallel detection system for EELS (see Fig. 1) consists of an $80^{\circ}$ magnetic sector field corrected to second order aberrations, three magnetic quadrupole lenses [12], and a thin single-crystal scintillator (YAG) lens-optically coupled to an intensified photodiode array (EG\&G PAR 1422).

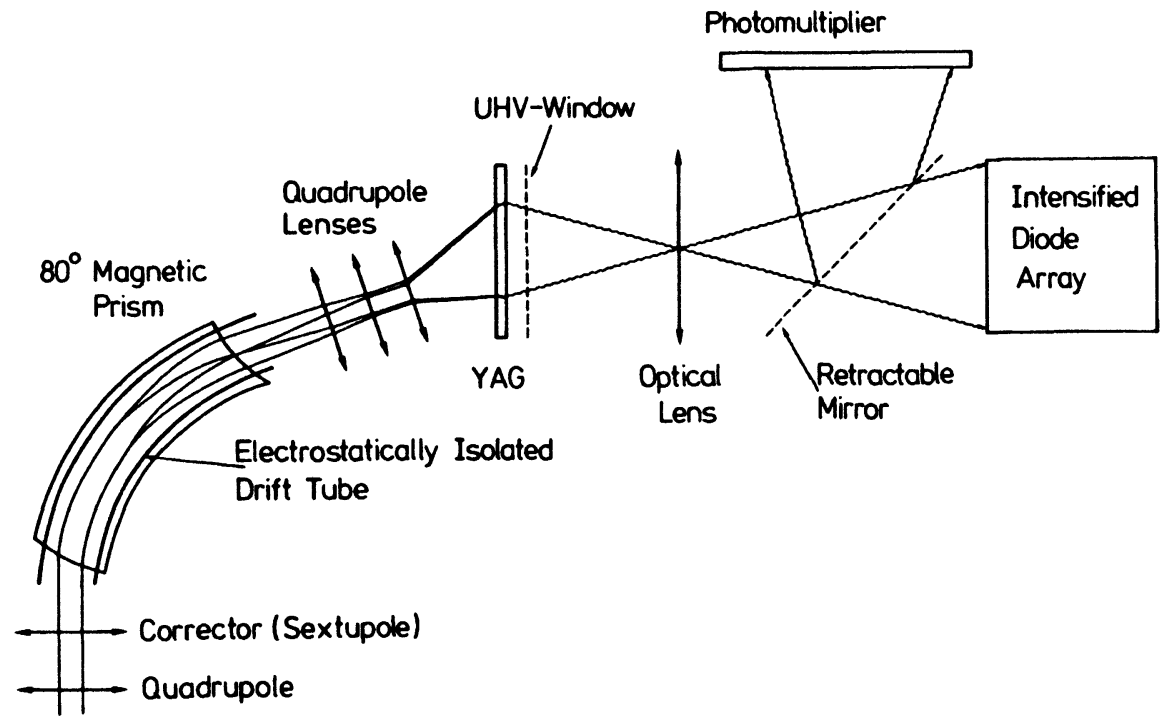

Fig. 1. - The parallel detector system for EELS. 
The photodiode array is controlled by an optical multichannel analyser (EG\&G PAR 1460). A known voltage applied to the electrostatically isolated drift tube allows the calibration of the energy losses. Bright field imaging is still possible by means of a mirror and a photomultiplier (Fig. 1). The parallel detector is described in detail in [8]. Background subtraction in the spectra was performed according to Trebbia [13]. All spectra were corrected for dark counts and for inhomogenous response of the photodiodes. The photodiodes were operated at a temperature of $-30^{\circ} \mathrm{C}$ for all measurements.

\section{Results.}

A high angle annular dark field image (atomic number contrast) of a MOVPE grown $\mathrm{GaAs} / \mathrm{GaAlAs}$ heterostructure is shown in figure 2. Using a probe current of $1 \mathrm{nA}$ and a probe diameter of $1 \mathrm{~nm}$ EEL spectra within the thick GaAs, GaAlAs, and AlAs layers were recorded with the parallel detector within 20 seconds. The spectra are shown in figure 3 . The background under the $\mathrm{Ga}$ edge is subtracted in all spectra. The $\mathrm{Ga}-\mathrm{L}_{2,3}$ edge starting at $1115 \mathrm{eV}$ is obvious for the GaAs and the GaAlAs spectrum. All spectra show the As- $\mathrm{L}_{2,3}$ edge at $1323 \mathrm{eV}$. The As- $\mathrm{L}_{1}$ edge at $1520 \mathrm{eV}$ is very weak. The Al-K edge at $1560 \mathrm{eV}$ is clearly visible in the GaAlAs and AlAs spectrum. The energy resolution obtained is better than $2 \mathrm{eV}$.

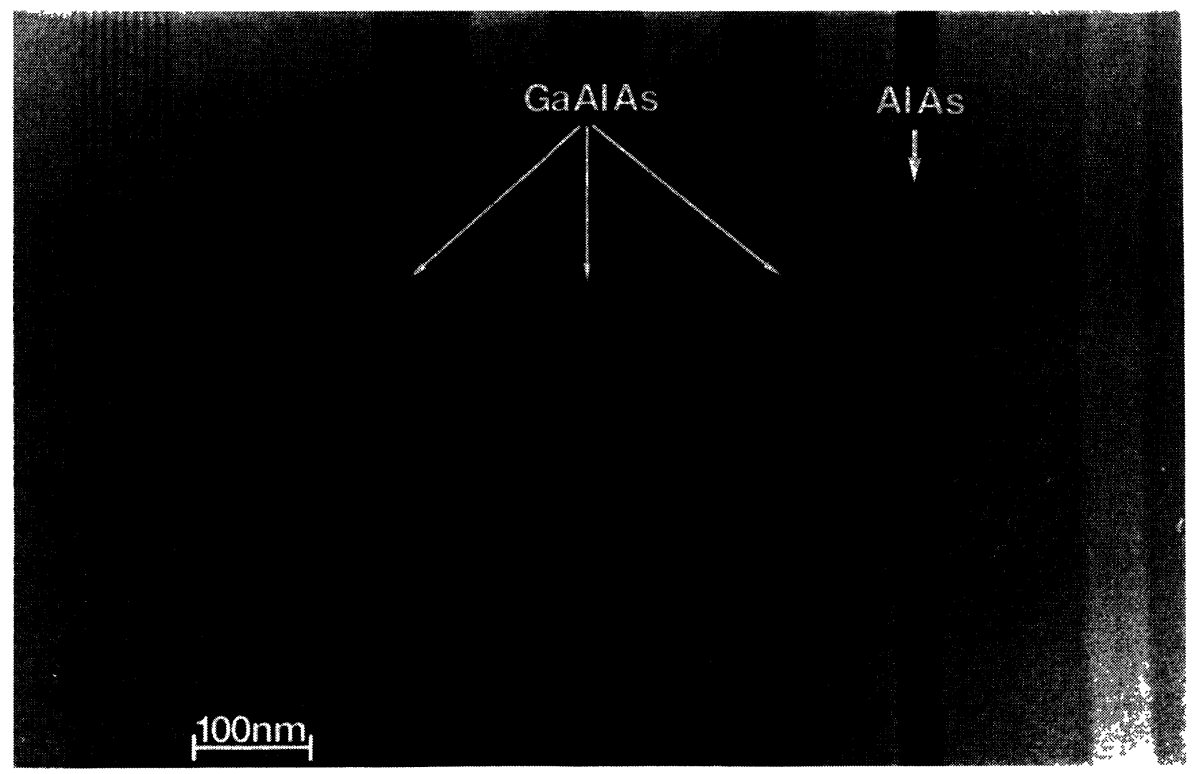

Fig. 2. - High angle annular dark field image (atomic number contrast) of a MOVPE grown GaAs/GaAlAs heterostructure.

As a next step narrower GaAs/GaAlAs layers were investigated. Figure 4 shows a high angle annular dark field image (atomic number contrast) of a GaAs/GaAlAs superlattice buffer layer. The GaAlAs layers are $1.8 \mathrm{~nm}$ thick. Figure 5 shows the GaAlAs spectrum recorded in the superlattice compared to a spectrum of GaAs recorded under identical conditions. Both spectra are background subtracted. Whereas a comparison of the $\mathrm{Ga}$-intensities is possible indicating a 


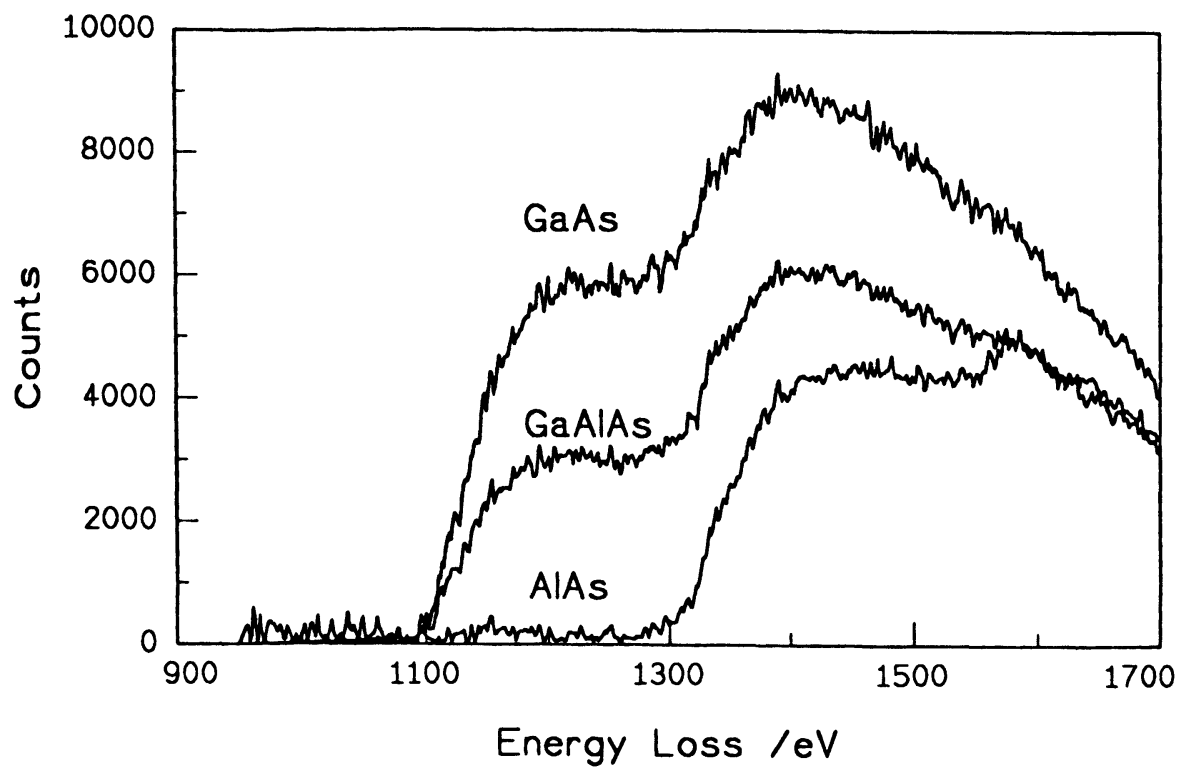

Fig. 3. - EEL spectra of $\mathrm{GaAs}, \mathrm{Ga}_{0.56} \mathrm{Al}_{0.44} \mathrm{As}$, and $\mathrm{AlAs}$ (probe current $1 \mathrm{nA}$, probe diameter $1 \mathrm{~nm}, 20 \mathrm{~s}$ recording time).

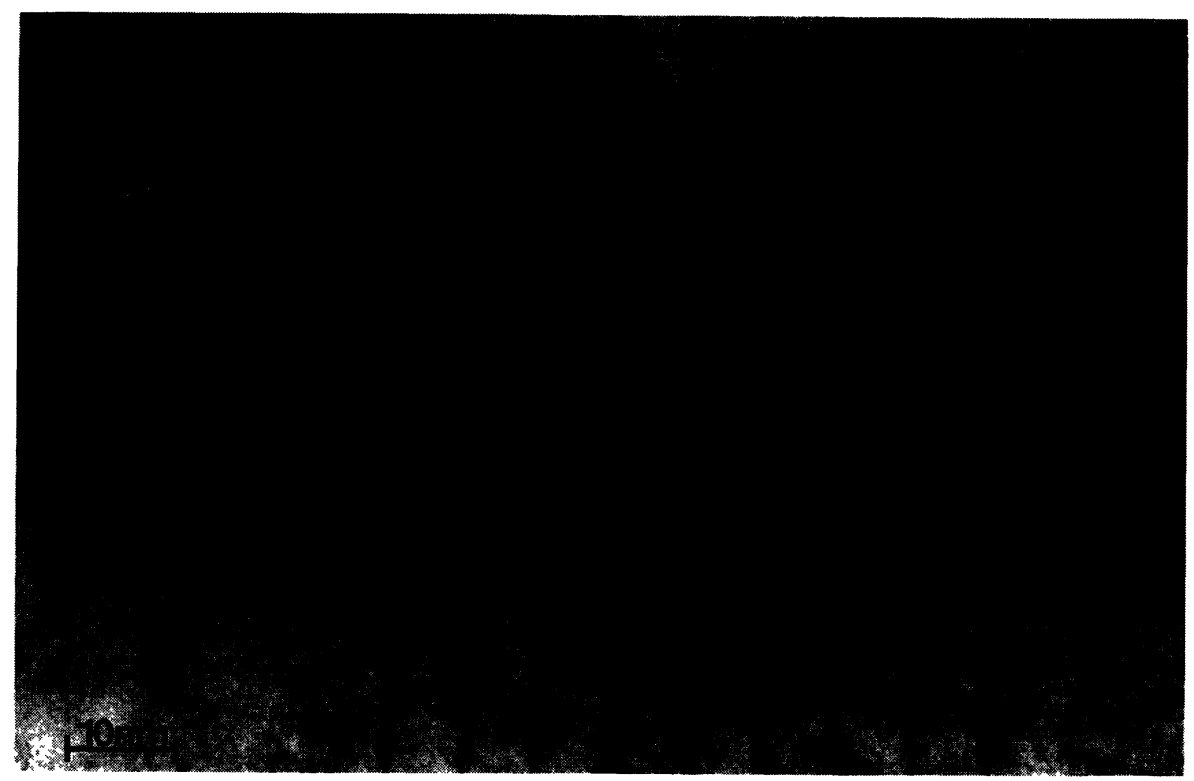

Fig. 4. - High angle annular dark field image (atomic number contrast) of a GaAs/GaAlAs superlattice buffer layer.

composition of $x=0.5$ for the $\mathrm{Ga}_{(1-x)} \mathrm{Al}_{x}$ As superlattice layers, a detection of the Al-K-edge cannot be done due to low signal to noise conditions. 


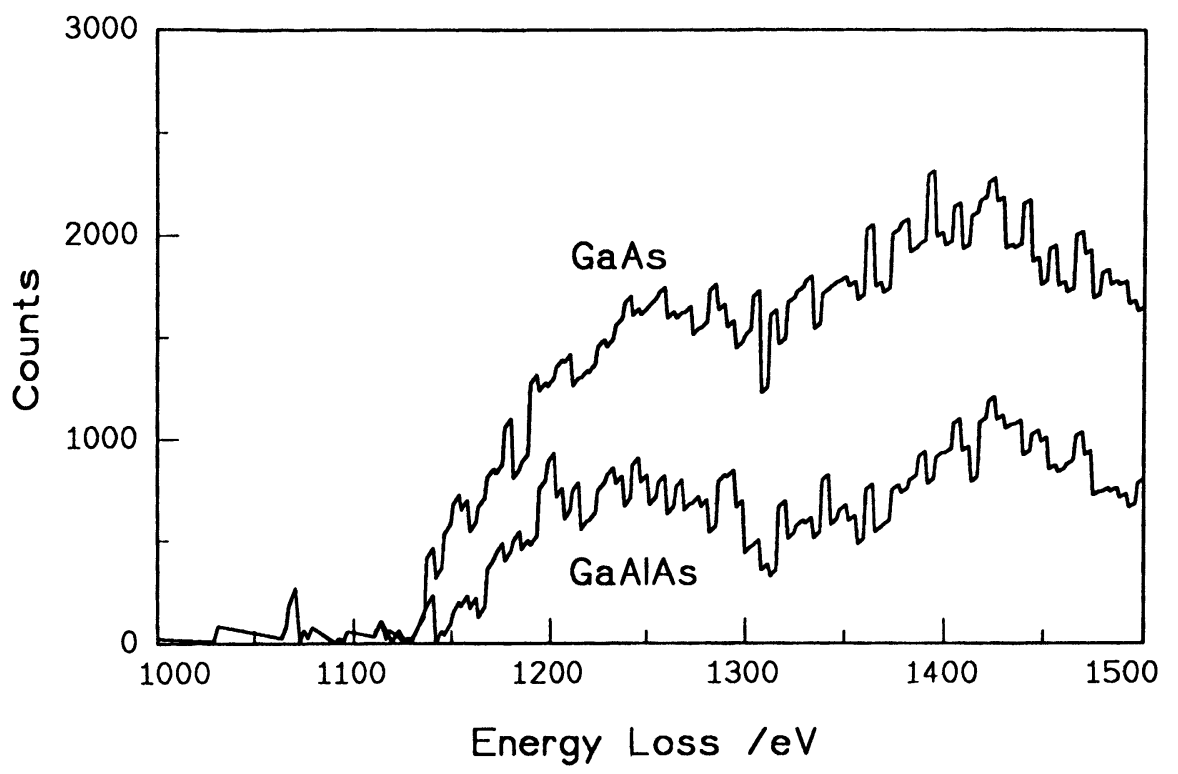

Fig. 5. - EEL spectra of $\mathrm{GaAs}$ and of $\mathrm{Ga}_{0.5} \mathrm{Al}_{0.5} \mathrm{As}$ recorded in the superlattice after background subtraction. (probe current $100 \mathrm{pA}$, probe diameter $0.5 \mathrm{~nm}, 20 \mathrm{~s}$ recordind time).

In a further step the probe current was reduced from $1 \mathrm{nA}$ to $5 \mathrm{pA}$ in four steps with ideally corresponding probe diameters from $1 \mathrm{~nm}$ to $0.2 \mathrm{~nm}$ (according to [5]). The EELS results for $\mathrm{GaAs}, \mathrm{GaAlAs}$, and AlAs are shown in figure 6. The four sets of spectra were recorded under identical conditions except probe current. The recording time for one spectrum was $20 \mathrm{~s}$. For the smallest probe current only the GaAs and AlAs spectra are plotted in order to allow distinguishing the spectra. It is obious that even for the smallest probe current and therefore for the smallest probe diameter the Ga edge and the As edge can give analytical information. The Al-K-edge is only visible for probe currents of $1 \mathrm{nA}$ (and more).

Facing the fact that the Al-K edge is difficult to detect the Al-L edge at $72 \mathrm{eV}$ was investigated. Figure 7 shows a (200) dark field image of the MBE grown GaAs/GaAlAs heterostructure as used for the EELS measurements of the Al-L edge. The arrows indicate the regions where spectra were taken. The results are shown in figure 8. Both spectra were recorded with a probe current of $1 \mathrm{nA}$. The difference between GaAs and GaAlAs is obvious. Background subtraction was not performed due to problems of background estimation in the low loss region. Using smaller probe currents than $1 \mathrm{nA}$ the Al-L edge was not clearly detectable.

\section{Discussion.}

Using typical beam parameters of the STEM (1 nA probe current, $1 \mathrm{~nm}$ probe diameter) combined with parallel detection of the EEL spectra it is possible to detect the Al-L and Al-K edge in a $\mathrm{GaAs} / \mathrm{GaAlAs}$ heterostructure with a spatial resolution better than $2 \mathrm{~nm}$, if the Al concentration $x$ is more than 0.2 in the $\mathrm{Ga}_{(1-x)} \mathrm{Al}_{x}$ As layers. For recording times less than $20 \mathrm{~s}$ and smaller probe currents than $1 \mathrm{nA}$ (and therefore better spatial resolution) the decreasing signal to noise ratio of the as recorded spectra does not allow the detection of $\mathrm{Al}$ edges. To overcome this probem 

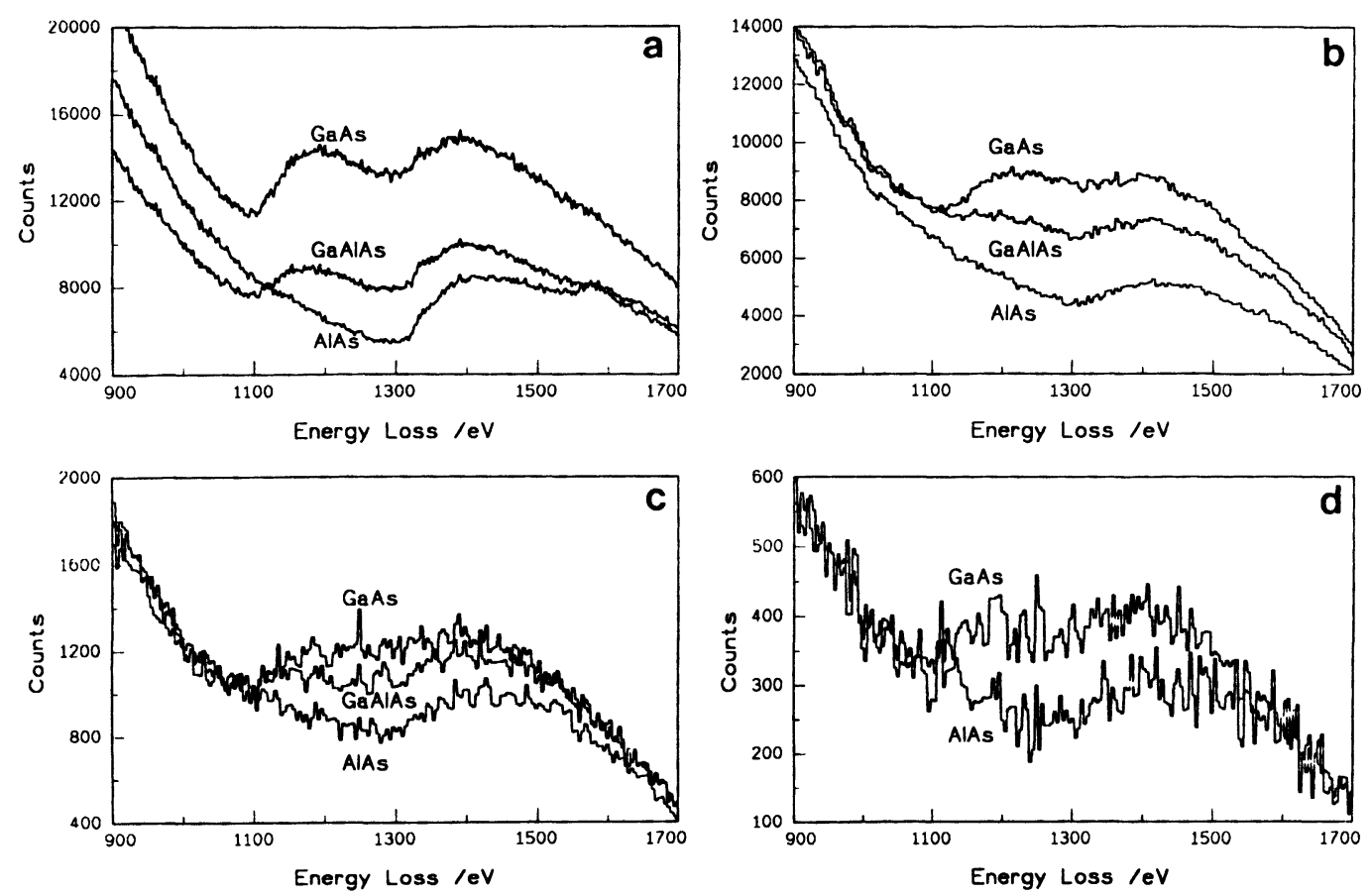

Fig. 6. - EEL spectra of GaAs, GaAlAs, and AlAs recorded under identical conditions as for figure 5 except probe current. The probe current was $1 \mathrm{nA}$ in a), $100 \mathrm{pA}$ in b), $15 \mathrm{pA}$ in c), and $5 \mathrm{pA}$ in d). The obtainable corresponding probe diameters vary from $1 \mathrm{~nm}$ to $0.2 \mathrm{~nm}$.

a special processing technique like second difference spectra acquisition [14] has to be used in future.

A further problem to get direct control of the $\mathrm{Al}$ concentration in GaAlAs via EELS is correct background estimation for the $\mathrm{Al}-\mathrm{L}$ and $\mathrm{Al}-\mathrm{K}$ edges. In both cases minor As edges (As- $\mathrm{M}_{4,5}$ at $42 \mathrm{eV}$ and $\mathrm{As}-\mathrm{L}_{1}$ at $1520 \mathrm{eV}$ ) in front of the $\mathrm{Al}$ edges do not allow to apply routine background subtraction methods for the quantification of the Al edges.

For quantitative microanalysis of $\mathrm{GaAs} / \mathrm{GaAlAs}$ heterostructures the $\mathrm{Ga}$-L edge is much more suitable. After background subtraction it is possible to determine the $\mathrm{Ga}$ concentration with an accuracy of $x \leq 0.05$ in $(1-x)$. For that purpose the Ga intensity recorded in a GaAs layer is used as an internal standard and compared to the $\mathrm{Ga}$ intensity recorded in a GaAlAs layer. From such data the Ga concentration can be determined and the Al concentration can be calculated.

The spectra taken with different probe currents demonstrate that very small probe currents $(5 \mathrm{pA})$ and probe diameters down to the range of $0.2 \mathrm{~nm}$ can be used to perfom chemical analysis of $\mathrm{GaAs} / \mathrm{GaAlAs}$ heterostructures.

In order to check the limits of spatial resolution with EELS it will be neccessary to record line scans at high energy losses $(1 \mathrm{keV}-2 \mathrm{keV})$ across heterostructures. The combination of a fieldemission STEM and parallel detection of EELS as described in this paper should allow to record such linescans within reasonable recording times (some minutes). 


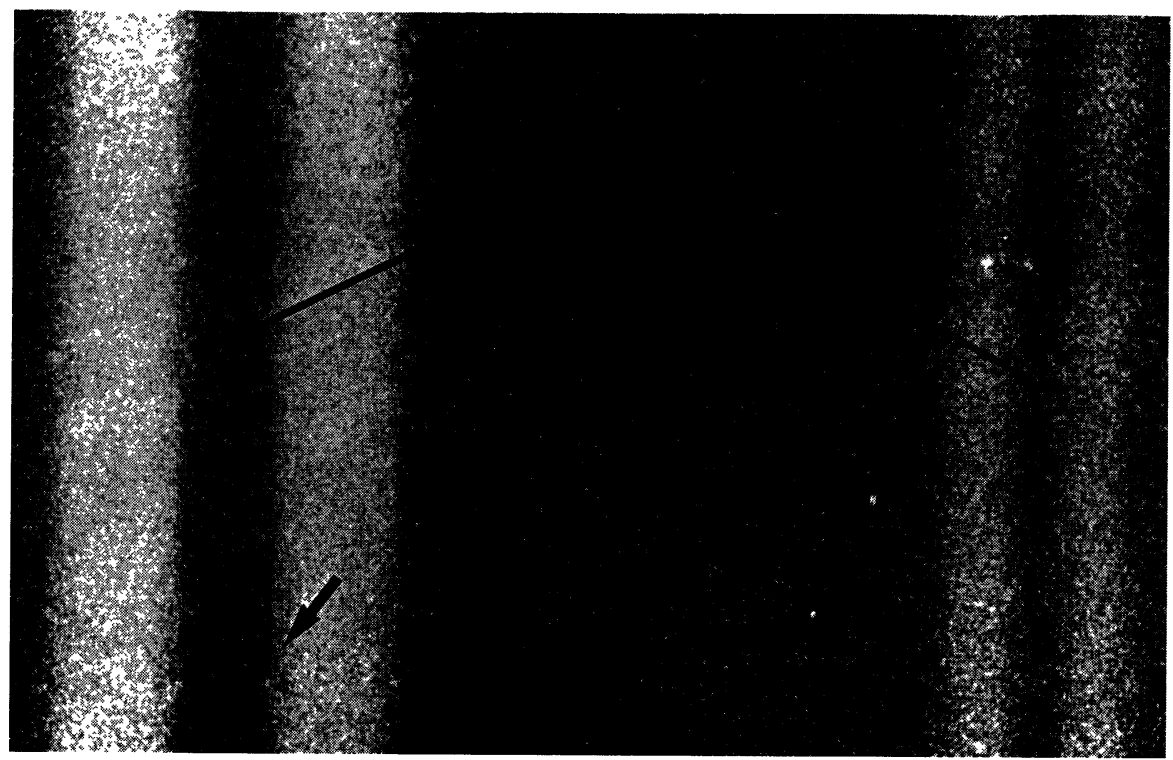

Fig. 7. - (200) dark field image of a MBE grown GaAs/GaAlAs heterostructure.

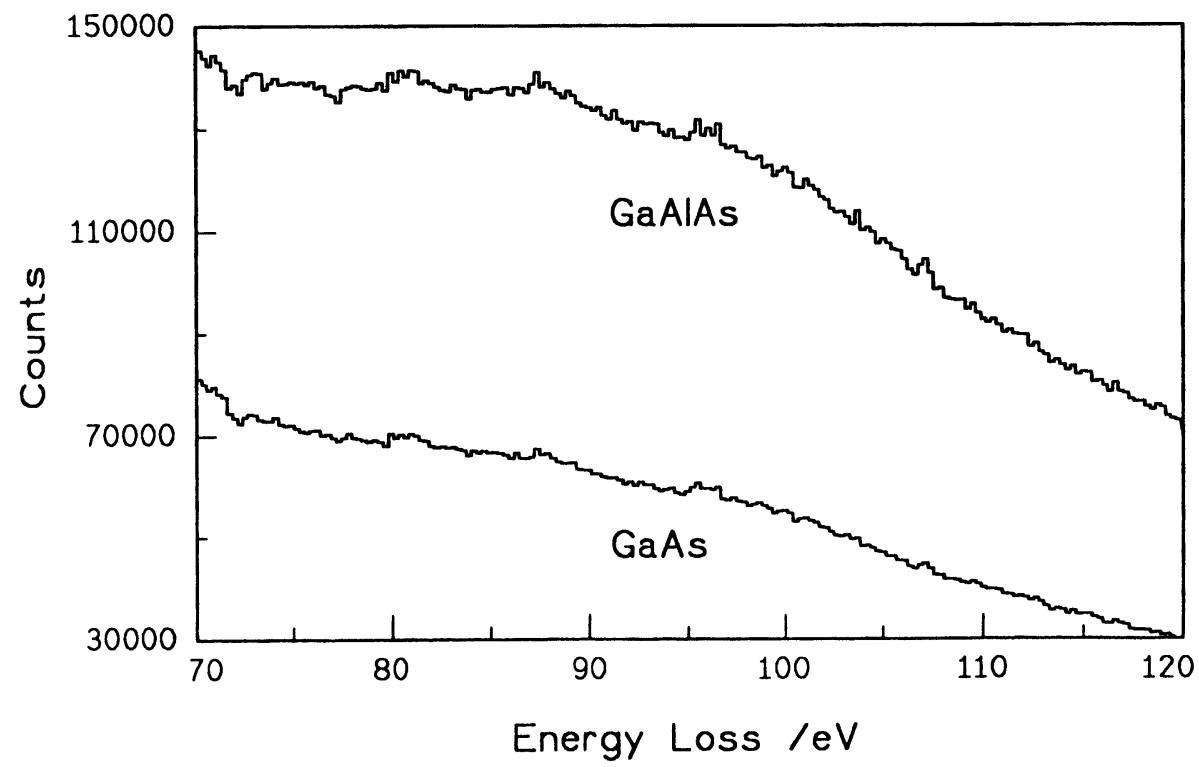

Fig. 8. - EEL spectra of GaAs and GaAlAs. The Al-L edge in the GaAlAs spectrum is visible (probe current $1 \mathrm{nA}$, probe diameter $1 \mathrm{~nm}, 2 \mathrm{~s}$ recording time). 


\section{Acknowledgements.}

The authors like to thank the following persons for their help: Prof. Dr. J.N. Chapman from the University of Glasgow assisted the development of this technique with many helpful discussions and participation in experiments. M. Maywald developed the background subtraction program. Specimen preparation was carried out by Miss K. Saemann. Specimens were supplied by F. Scheffer from the department for Solid State Electronics of Duisburg University. This work was financially supported by the Deutsche Forschungsgemeinschaft within the Special Collaborative Program 254: Very High Frequency and Very High Speed Circuits Based on III-V Compound Semiconductors.

\section{References}

[1] STŐRMER H.L., "Electron Mobilities in Modulation-Doped GaAs-(Al,Ga)As Heterostructures", Surf. Sci. 132 (1983) p. 519-526.

[2] KRESSEL H., BUTLER J.K., "Semiconductor Lasers and Heterojunction LED's" (Academic Press, New York, San Francisco, London, 1977) p. 360, p. 413.

[3] DAPKUS P.D., MAA B.Y., CHEN Q., JEONG W.G., "Atomic Layer Epitaxy of GaAs and Related Compounds", 5 th Int. Conf. on MOVPE, 18-21 June 1990, Aachen, Germany.

[4] JoY D.C., ROMIG A.D., GolDSTEIN J.I., "Principles of Analytical Electron Microscopy" (Plenum Press, New York and London, 1986) p. 270.

[5] PENNYCOOK S.J., "Z-Contrast STEM For Materials Science”, Ultramicroscopy 26 (1988) p. 239-252.

[6] EgERTON R.F., CROZIER P.A., "A Compact Paralled-Recording Detector For EELS", J. Microsc. 148 (1987) p. 157-166.

[7] QuANDT E., KoHL H.J., Le BARRE S., NIEDRIG H., "Parallel Detection of Electron Energy Loss Spectra For Measurement of Localization Contrasts in Electron Channeling Patterns", Beitr. Elektronenmikroskop. Direktabb. Oberfl 21 (1988) p. 65-72.

[8] LAKNER H., BALK L.J., KUBALEK E., "A Parallel Detector For Electron-Energy Loss Spectroscopy In A Field-Emission Scanning Transmission Electron Microscope (STEM)", Beitr. Elektronenmikroskop. Direktabb Oberf. 22 (1989) p. 241-248.

[9] LORETTO M.H., "Analytical Electron Microscopy of Electronic Materials", Inst. Phys. Conf. Ser. 87 (1987) p. 633-642.

[10] GibBon A.J., ChaPman J.N., Cullis A.G., "High-Angle Annular Dark Field Imaging of AlGaAs/GaAs Multilayer Structures", Inst. Phys. Conf. Ser. 93 (1988) p. 403-404.

[11] BrTHELL E.G., STOBBS W.M., "Composition Determination in the GaAs/(Al,Ga)As System Using Contrast in Dark-Field Transmission Electron Microscope Images", Phil. Mag. A 60 (1989) p. 39-62.

[12] KRIVANeK O.L., AhN C.C., KeENEY R.B., "Parallel Detection Electron Spectrometer Using Quadrupole Lenses", Uttramicrosc. 22 (1987) p. 103-118.

[13] Trebbia P., "Unbiased Method For Signal Estimation in Electron Energy Loss Spectroscopy, Concentration Measurements and Detection Limits in Quantitative Microanalysis: Methods and Programs", Ultramicrosc. 24 (1988) p. 399-408.

[14] LEAPMAN R.D., "A Comparison of PEELS and EDXS Detection Limits", Lake Tahoe Workshop on EELS, 17-22 August 1990, Lake Tahoe, U.S.A. 